\title{
Students' response to English language course management systems: a case study
}

\author{
Alan Weber \\ Weill Cornell Medical College, Qatar
}

\section{Introduction}

E-learning, here simply defined as education delivered or facilitated by the internet, has become increasingly important throughout the Gulf region. Direct governmental investment in e-learning has been substantial, with the largest spender Saudi Arabia investing USD 125 million in 2008 and the UAE spending a projected USD 72.6 million in 2010 (MENAFN, 2008; Al Bawaba, 2008). E-learning has been integrated into larger national ICT development strategies in Qatar, Oman, and Bahrain, who all plan to move during the next 10-20 years from hydrocarbon-based economies to knowledge-based societies. Course Management Systems (CMS) are one of the most wide-spread means of delivering online course content and facilitating blended learning, and have rapidly taken hold in Gulf educational systems. A typical course management system such as Blackboard (Blackboard Inc., 2011a) is a suite of software applications that allows students to upload, download and send course documents, communicate with the instructor both live and by email, access live chat with other students, post messages to bulletin boards, take quizzes online, collaborate with other learners online, and retrieve information from the internet. Sophisticated software plugins, which include multimedia textbook material, and tools for practicing almost any basic math or chemistry subject, are also available from third party vendors. ANGEL (Blackboard Inc., 2011b) and Moodle (Moodle, 2011), the two major alternatives to Blackboard, are very similar in functionality, but vary greatly in layout, customizability, and available plugins, which are primarily written for the Blackboard platform. In addition, Moodle is an open source product, meaning that the source code is freely distributed to developers.

Usage of Blackboard, the most popular CMS, increased dramatically at United Arab Emirates University (UAEU) from 1200 users in 2002 to 8000 users by 2005 (Guessoum, 2006; Hussein et al., 2007). Similarly at Sultan Qaboos University in Oman (SQU), WebCT (a CMS acquired and now being decommissioned by Blackboard, Inc.) was implemented in 2001 with 8 online courses comprising 981 users. Usage consequently jumped in 2002 to over 40 courses and 3001 students (Al-Senaidi, 2009; Al-Musawi, 2004, 2007).

Besides providing benefits already demonstrated in the West - anytime/anywhere education, low cost dissemination of learning objects to large learning populations, collaborative learning environment versus banking model of education, etc. - CMS's and e-learning in general have a unique and important role to play in the Gulf in providing educational opportunity to two specific groups: homebound disabled learners and conservative Muslim students attempting to avoid the mingling of unmarried members of the opposite sex, a prevalent taboo throughout the Gulf region. Disabled Gulf citizens are often cared for at home and do not appear regularly in public due to both lack of accessible facilities and fear of social stigmatization and discrimination (Turmusani, 2003; Abdul-Haq, 2008). Higher education in Saudi Arabia is gender segregated, and lecturers sometimes transmit lectures to single sex groups in separate rooms via closed circuit TV, an obvious precursor to online learning. E-learning can aid in maintaining this gender-segregated environment. 
Gender segregation is practiced in the vast majority of Gulf schools and universities at all levels in some form through separate schools, campuses, classrooms, or seating within classes and eating areas - i.e. self-segregation (Weber, Development, 2010a). Paradoxically, through the online collaborative environment, restricted social roles can also be broken, and online activities may serve as a bridge to more gender equity, if that is in fact an educational and social goal (for example in Qatar, whose leadership is promoting female entrepreneurship, expanded political participation for women, and female higher education). This area is highly controversial, however, and some local conservative Gulf educators have cautioned that unsupervised online chat may not be appropriate for the Gulf cultural context (Al-Hunaiyyan et al., 2008; Akinyemi, 2003). E-learning is also a central concern for the overseas branch campus (a satellite campus of a main campus in another country), since these kind of institutions need to share resources with the main campus, in many cases electronically via tele-conferenced classes, to alleviate regional shortages of qualified faculty (Weber, 2009, 2010c; Reilly, 2008, 2009).

Also, the professional level expatriate workforces in the Gulf, which in countries like Qatar and the UAE substantially outnumber the local population, often face long inflexible work hours with few professional development opportunities. As an example of how e-learning can serve professional development, new laws in Saudi Arabia and UAE now require medical professionals to maintain a certain number of Continuing Medical Education (CME) credits for relicensure to insure that health professionals are keeping current with knowledge in their field. Increasingly, busy physicians and nurses are turning to web based e-learning modules or webinars from companies such as the Gulf CME Online website to update their medical knowledge (Weber, 2010b).

Starting out children at an early age with e-learning, such as the K-net virtual learning environment currently being phased into Qatar's primary and secondary schools with Arabic and English interfaces, helps to build computer literacy. Young adults trained in e-learning will be more adept in using the emerging online e-government services and e-health services planned for Qatar, such as online public health information.

The research presented here is particularly relevant to the Gulf region, because Gulf cultures are widely recognized as oral-based cultures, and face-to-face interaction takes precedence over written communication (Melikian, 1981; Al-Misnad, 1985; Graham, 1978). The online environment, specifically text-based chat, is a new and unique hybrid form of communication (informal, yet written) for a region that has enthusiastically embraced the mobile phone as an extension of its orality.

\section{Background}

On May 6, 2009, Blackboard, Inc. acquired its rival CMS ANGEL Learning, Inc. Now the major difference in CMS products will be between proprietary source code products such as Blackboard and open-source products such as Moodle and Sakai, in which licensing is free. Since the merger provided Blackboard with such a large share of the CMS market, the U.S. Justice Department immediately launched an antitrust investigation of the company. Some observers predict that current trends in the CMS marketplace, such as mega-mergers, will mean that "more professors will turn to free, general-purpose Web 2.0 tools to run course blogs and discussions to avoid Blackboard, bringing an eventual death to the concept of course-management systems" (Young, 2009).

There has been a great deal of recent interest in Moodle, an open source product which provides considerable cost savings for large educational systems such as U.S. community colleges. A widely quoted and extensive study comparing Moodle and Blackboard (Randall, 2009) was carried out in the North Carolina Community College System. Surveying both faculty $(n=199)$ and students $(n=1,127)$, 
researchers measured satisfaction with course navigation, ease of use, communication and collaboration tools, course content, assessment, and upload capabilities, variables which were also measured in the current study. Very few statistically significantly differences were discovered between the two CMS's. However, analysis of raw student data by MANOVA surprisingly revealed that students who perceived their instructors to be more comfortable with CMS's in general rated the CMS functionality higher, regardless of which CMS was used. The conclusion of the report was "ultimately, Blackboard and Moodle are not that different" (Randall et al., 2009: 40). This conclusion supports the general results of the present study and was echoed by one female student in the WCMC-Q study: "There is no perfect system. There are systems with different options and features that you can choose from."

There have been sporadic attempts to develop entirely Arabic language e-learning systems, such as the Wiki-based Arabic language statistics system at Humboldt Universitat, Berlin and the Makkah E-learning system of Dr. Ali $\mathrm{H}$. Abureesh at Umm Al-Qura University in Makkah, KSA, with an English interface geared towards native Arabic speakers (Ahmad et al, 2007; Abureesh, 2003). However, learning objects and course management systems are created primarily in the English language. As is well known to Arabic language programmers, there are still serious coding, standards, compatibility, and meta-data issues to be resolved in using the Arabic language on the internet.

\section{Methodology}

The aim of this study was to construct a holistic picture of Gulf students' use of English language course management systems using both quantitative data (end of semester questionnaire, $n=13$ sample size) and over 238 pages of qualitative data from WCMC-Q students, including a student technology notebook, a formal student essay comparing the three CMS's, and the author's personal experience in using various CMS's for 4 years in Education City, Qatar. The research attempts to uncover any current challenges or concerns that students are encountering using the English language interfaces of current $\mathrm{CMS}^{\prime}$, as well as any potential educational benefits. Research questions were as follows:

1. Are CMS's in general valuable to the learning experience in the Gulf region?

2. Does gender impact students' satisfaction with and ease of use of English language CMS's?

3. Do students prefer traditional class activities (in-class discussion, peer review, quizzes) or their analogous electronic equivalents (synchronous chat, electronic peer review, online quizzes)?

Weill Cornell Medical College in Qatar (WCMC-Q) is a branch campus of Weill Cornell Medical College in New York City, and is a member of Education City, a 14-square kilometer site west of Doha housing 6 U.S. branch campuses, including Carnegie Mellon, Northwestern, and Texas A\&M Universities. The WCMC-Q student sample in this study is a mixture of 13 freshman Qatari, Gulf, and international students, 9 of whom spoke Arabic as their primary language and English as their secondary language, and 4 primarily non-Arabic speakers (Urdu, 2 English, Tamil). Most were newcomers to CMS's with an average of 2.3 semesters of experience using CMS, and the sample can therefore be classified as novice users.

In the author's Spring 2009 History of Medicine and Writing class entitled "The Story of Medicine," a First Year Writing Seminar conducted under the guidelines of the Knight Writing Institute in Ithaca, New York, course content was divided equally into 3 time periods. First, Blackboard 7.3 was used for the first third of classroom activities, then Moodle 1.7.6 was used for the second third, and ANGEL 7.2 for the final third. The exact same set of class activities were scheduled for each of the 3 time periods and the 3 CMS's: posting Key Concepts to a bulletin board (asynchronous chat), online quizzes, online class 
discussions (synchronous chats), email, and electronic peer review (dropbox or email feature). For each online activity in each CMS, an analogous paper or traditional activity was planned in order to compare electronic activities versus traditional ones. For example, students took an equal number of online and paper-based quizzes, and engaged in peer review not only by exchanging and marking up hard paper copies face-to-face, but also by working entirely online using a document drop box and MS Word track changes functionality.

On the last day of the semester, a third party administered a signed consent form and a 47-item questionnaire comprising basic demographic questions, and a simple set of twelve 5-point Likert-scale (Excellent, Good, Average, Fair, Poor) satisfaction questions for each CMS, creating three summated Likert scales. Likert-scale items are listed below, and were designed to measure students' overall satisfaction with each CMS:

1. Ease of signing up

2. Ease of accessing website

3. General website reliability

4. Ease of use of interface

5. Chat function

6. Course documents downloading

7. Email Announcements

8. Bulletin Board

9. Electronic quizzes

10. Electronic Peer Review

11. Email

12. Overall value to your learning

In addition, for each CMS, six open-ended questions were asked (listed in Table 3, below), including: "What are the benefits in using Blackboard/ Moodle/ ANGEL?" and "What are the disadvantages to using Blackboard/ Moodle/ ANGEL?" These open-ended questions provided a general assessment of the pros and cons of the three systems. Due to the very small final sample size $(n=13)$, definitive conclusions and inferences cannot be drawn from the statistical analysis of the quantitative data alone, but the data did reveal some general trends corroborated both by other studies and by the large amount of qualitative anecdotal evidence collected from the same student sample. Similar to the Likert-scale questions, the open-ended questions were also designed to measure the general degree of satisfaction of students with each CMS with respect to the ease of use and the contribution to the learning experience:

1. What are the benefits in using [Blackboard/Moodle/ ANGEL]?

2. What are the disadvantages to using [Blackboard/Moodle/ ANGEL]?

3. Which course management system did you prefer to use and why?

4. Did you prefer electronic chats or regular class discussion and why?

5. Did you prefer electronic quizzes or paper quizzes and why?

6. Did you prefer electronic peer review or paper, in-person, peer review and why? 


\section{Results and discussion}

\section{Which CMS scored highest?}

Descriptive statistics were calculated and graphed in MS Excel. Means of the 5-point Likert scale questions indicating the students' satisfaction with various features with each CMS are presented in Figure 1. ANGEL scored slightly higher overall in total raw scores on the questionnaire, with the highest satisfaction means in 6 of the 12 categories, with Moodle and Blackboard both tied for 3 each in the remaining 6 categories. For all CMS's, both email and electronic peer editing scored the lowest. Students indicated in anecdotal responses that they were more comfortable using their customary email program, and that paper and face-to-face peer review of essays was actually more efficient. On the most important Likert scale question - "overall value to learning" - all 3 CMS's scored between 3.4-3.6, indicating that students perceive that all these systems do add value to the learning experience.

Single factor ANOVA $(a=.05)$ was performed on the 3 summated Likert scales representing the latent variables "Satisfaction with Blackboard," "Satisfaction with Moodle," and "Satisfaction with ANGEL." The $F_{(2,36)}$ value was .5547 , less than $F_{\text {crit }}=3.259$. This indicates that despite the seemingly higher positive response to ANGEL, there were no statistically significant differences overall among student satisfaction with the three systems.

The anecdotal evidence was widely scattered, with some students preferring particular features of one CMS, and other students preferring others; but ANGEL came out slightly ahead in the number of positive anecdotal comments. One must keep in mind in future study design with larger data sets, however, that ANGEL was the final CMS used in the course, and that the greater level of experience with using CMS's may have been a factor leading to greater satisfaction with ANGEL and skewing the final results, especially since the study population were essentially novice users.

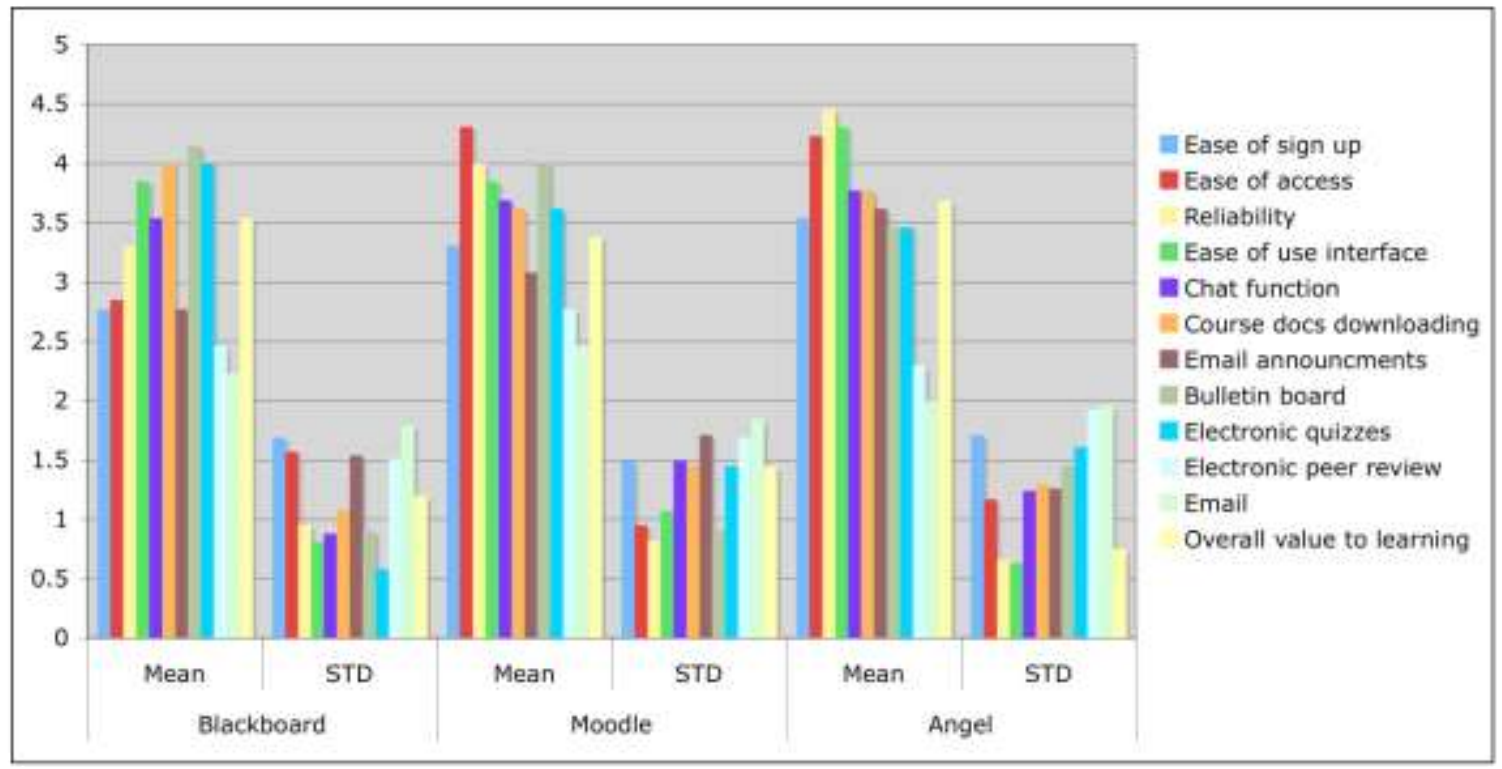

Figure 1: Means and standard deviations of satisfaction questions for Blackboard, Moodle and ANGEL (5-point Likert scale). 


\section{Students' Preference of CMS}

Did students prefer any of the 3 different CMS? ANOVA Single factor test was carried out at $a=0.05$ and indicated that there were no differences in students' average satisfaction ratings with each of the systems $(F=0.1613$ / Fcrit $=3.4028$ and $p=0.8519>0.05)$. The conclusion was that they did not face any barriers in ease of use and satisfaction while using any one particular CMS.

\section{Differences in male/ female satisfaction with CMS: some significant considerations}

The existing quantitative data was not sufficient to provide statistically significant information about male/ female differences in CMS use. However, anecdotal evidence and observation indicates that males mastered the CMS software more rapidly, since they tended to be more vocal in and out of class and demonstrated a greater tendency to ask for assistance from the instructor and IT staff. One female Arab student wrote in her technology notebook "it [using the CMS] made us face some problems because we were not used to such things and we did not know how to solve these technical problems." By the time that ANGEL was used in the final third of the course, however, the females expressed similar levels of satisfaction and ease of use, i.e. they had 'caught up.'

These observations raise several interesting research questions for future investigations: are there significant differences in Gulf male and female students' access to computers, number of hours spent on computers, and patterns of help-seeking behavior (i.e. gender differences in computer literacy and how literacy develops)? One would expect, judging from traditional Gulf social patterns, to see significant differences in male/ female computer use and help-seeking behavior; for example, one might expect that females may more often turn to female peers and online help resources rather than ask assistance from male professors or IT staff, who are predominantly male in the Gulf. Studies from the United States indicate that computer science is still a male domain: for example, the proportion of Bachelor degrees in Computer Science awarded to women decreased from 34\% to 25\% between 1982 and 2002, while women made substantial gains in Engineering, Physics and Chemistry (Sanders, 2010). It would be valuable for educational planners to know if this pattern also exists in the Gulf region.

\section{Do Students in the Gulf prefer traditional activities or electronic?}

From the anecdotal data and free response questions, several clear trends emerged. Generally there was great enthusiasm for the new learning environment: any activity involving technology will have high status among younger Gulf learners, and student motivation for learning is a key issue in the region. Student motivation to excel in or even complete degree programs is a serious Gulf educational concern, particularly with respect to male students (Jolo, 2007; Gonzalez et al., 2008).

CMS email was viewed as redundant and not useful (students most often used their existing preferred email client). The majority of students preferred paper peer editing versus using track changes function of MS Word and exchanging papers electronically. They felt paper provided greater speed and flexibility for drawing arrows, boxes, and comments.

Document downloading, i.e. having the syllabus, course assignments, instructions, and supplementary readings available on the CMS website, was consistently cited as one of the primary advantages of CMS's and greatly aided students in organizing their work.

Electronic quizzes met with an overwhelmingly positive response, with some qualifications. A male Arab student noted: "It was a good experience because it trains me for the future quizzes and exams that I will be taking online in the medical school." Several students expressed concern about the opportunity for cheating that arises in online quizzes, i.e. the ability to access web resources and the instant quiz 
feedback which can be shared with another student, etc. However, Moodle has posted a detailed Effective Quizzes Guide, and many universities have developed their own policies and recommendations involving such practices, for example, as invigilation and individual randomization of questions (Moodle, 2009; UCL, 2010). Thus proper design of online quizzes by instructors can greatly reduce incidents of cheating.

Any editing, spelling or grammar check tools available for online text boxes (quizzes or bulletin boards) were highly praised by Arabic-speakers in particular, because of the difficulties of hand writing English on paper and the lack of confidence in their penmanship, spelling, and grammar. This response was typical: "I did much better in the electronic quizzes since I had the complete freedom to edit, cut, and add anything any time in the exam. In the hard copy quizzes, it was bothersome to edit my answer; no one would like to hand in a dirty paper full of editing" (male Arab student).

The Chat function provoked the most interest in the class (the class participated in 6 full period chats, 2 per CMS). All comments about chat were initially positive, except for two students who believed the nuances of face-to-face interaction were missing. Four female Arabic speaking students indicated specifically that they felt more comfortable in the virtual environment. One veiled student wrote: "So I felt more flexible writing my ideas and involved in such a way and not requiring me physically in the class room and everyone staring at me while I am speaking." A male Arabic speaker commented: "Experiencing that [chat] was just amazing, usually in class I get nervous and I can't talk very effectively, miss points here and there. However, by using the online chat, I had enough space to express my thought and share them with my classmates. I also noticed that many students who were quiet in the class were also active in the online chat." By the end of the semester, however, according to the technology notebooks, about half of the students believed that online chats could augment class discussion by creating a more relaxed environment, but should not replace face-to-face interaction. They recognized that some important linguistic cues in face-to-face discussion are missing in online chat.

\section{Conclusion}

The conclusions of this study indicate that more data-driven research is needed in the area of Arabic speakers' use of CMS's and online learning in general, specifically on differences in gender, culture, and language in online learning environments. Other future related studies could include comparisons of English language CMS's with Arabic interfaces, as in Blackboard 7.x introduced in 2006-2007 and currently implemented at Qatar University. The obviously complex and interlinked issue of gender and computer literacy should be the subject of more focused studies with larger datasets. In some cases, girls will have unequal access to both computer and general educational resources due to traditional role models, while in other cases they may have advantages over males, such as in the UAE where male higher education enrollment is only about $28 \%$ of total enrollment.

There appear to be few major overall usability and satisfaction concerns in English language CMS adoption among this group of Gulf students, except possibly the gender and cultural issues cited above that may be related to internet usage and computer literacy in general. The two major concerns, therefore, for educators and institutions in adopting CMS's in the Gulf will obviously be cost and whether the software produces the desired educational outcomes. Ultimately, what is the instructor attempting to achieve in the classroom, and how can the CMS facilitate these goals? Open source products like Moodle (free licensing) will roughly cost in the tens of thousands of US dollars for institutional-wide deployment and the cost of Blackboard style products may reach into the hundreds of thousands of US dollars, including the license fee. It is almost impossible to generalize CMS system implementation costs, however, since they are highly dependent on individual institutions' existing ITC 
infrastructure and support services. Another key question for CMS adoption is 'are instructors, students, and IT support teams adequately trained for using the technologies?'

\section{Acknowledgments}

This study was supported by the Weill Cornell Medical College - Qatar and Qatar Foundation. I would like to thank Dean Michael Johnson, Dean Javaid Sheikh, Dr. Mary Ann Rishel, Dr. Mary Ann Baker, and Dr. Krystyna Golkowska for their support, encouragement and comments.

Internal Review Board for the ethical use of human subjects was granted by Weill Cornell Medical College in Qatar on 23 April 2009 (\#2009-0002).

\section{References}

Abdul-Haq, A.K. (2008). Disability. In L.S. Nasir and A.K. Abdul-Haq, (Eds). Caring for Arab Patients: A Biopsychosocial Approach. Abingdon: Radcliffe.

Abureesh, A.H. (2003-2010). Makkah E-Learning. Retrieved from http://www.makkahelearning.net/

Ahmad, T., Hardle, W., and Klinke, S. (2007). Using Wiki to build an e-learning system in statistics in Arabic language. Proceedings of the World Academy of Science, Engineering and Technology. Retrieved from http://www.waset.org

Akinyemi, A. (2003). Web-Based Learning and Cultural Interference: Perspectives of Arab Students. In A. Rossett (Ed.), Proceedings of World Conference on E-Learning in Corporate, Government, Healthcare, and Higher Education 2003 (pp. 1858-1862). Chesapeake, VA: AACE.

Al Bawaba. (2008, Jan 15). UAE's E-learning Market Grows by 26 per cent to Reach USD 72.6 Million by 2010. Retrieved from http://www1.albawaba.com/news/uae\%E2\%80\%99s-e-learning-market-grows-26cent-reach-usd-726-million-2010

Al-Hunaiyyan, A.L., Al-Huwail, N., Al-Sharhan, S. (2008). Blended E-Learning Design: Discussion of Cultural Issues. International Journal of Cyber Society and Education, 1(1), 17-32.

Al-Misnad, S. (1985). The Development of Modern Education in the Gulf. Ithaca: Cornell University Press.

Al-Musawi, A.S., Abdelraheem, A.Y. (2004). E-learning at Sultan Qaboos University: Status and future. British Journal of Educational Technology, 35(3), 363-67.

Al-Musawi, A.S. (2007). Current status of educational technologies at Omani higher education institutions and their future prospective. Educational Technology Research and Development, 55(4), 395-411.

Al-Senaidi, S., Lin, L., Poirot, J. (2009). Barriers to adopting technology for teaching and learning in Oman. Computers \& Education, 53(3), 575-590.

Blackboard Inc. (2011a). Blackboard. http://www.blackboard.com/

Blackboard Inc. (2011b). ANGEL. http://www.blackboard.com/Platforms/Learn/Products/ANGELEdition.aspx

Gonzalez, G., Karoly, L.A., Constant, L., Salem, H., Goldman, C.A. (2008). Facing Human Capital Challenges of the 21st Century: Education and Labor Market Initiatives in Lebanon, Oman, Qatar, and the United Arab Emirates. Santa Monica: RAND. 
Graham, H. (1978). Arabian Time Machine: Portrait of an Oil State. London: Heinemann.

Guessoum, N. (2006). Online learning in the Arab world. elearn Magazine. Retrieved from http://www.elearnmag.org/

Hussein, M.I., Al-Muhtaseb, S., El-Sawy, K., Haggag, M., Shahin, T. (2007). Evaluation of IT-based active learning project at the UAE University College of Engineering case study. Emirates Journal for Engineering Research, 12(1), 37-42.

Jolo, H.A. (2007). Educational Outcomes and Labor Market Based on Supply and Demand: A Qatari Perspective. In A. Ahmed (Ed.). World Sustainable Development Outlook 2007 (pp. 44-51). Sheffield: Greenleaf.

Melikian, L. (1981). Jassim: A Study in the Psychosocial Development of a Young Man in Qatar. London: Longman.

MENAFN. (2008, Apr 23). KSA's elearning industry to touch $\$ 125 \mathrm{~m}$ in 2008. Retrieved from http://www.menafn.com/qn_news_story_s.asp?Storyld=1093194010

Moodle (2010). Effective Quiz Practices. Retrieved from

http://docs.moodle.org/en/Effective_quiz_practices

Moodle (2011). Moodle.org. http://moodle.org/

Randall, B., Sweetin, J., Steinbeiser, M.A.. (2009). The Open Source Collaborative: Moodle Assessment Report. Wordpress. Retrieved from http://oscmoodlereport.wordpress.com/

Reilly, B. (2008). Digital Encounters: Using Information Technology in an Overseas Branch Campus. The History Teacher, 41(4), 53-41.

Reilly, B. (2009). Globalizing the Classroom: Lessons Learned from EC Teleclasses. Paper presented at the Fourth Annual Liberal Arts Conference Higher Education in the GCC: Emerging Trends and Models, American University of Kuwait.

Sanders, J. (2010). Gender and Technology in Education: A Research Review. Accessed 12 Dec 2010. Retrieved from http://www.josanders.com/pdf/gendertech0705.pdf

Turmusani, M. (2003). Disabled People and Economic Needs in the Developing World: A Political Perspective from Jordan. Aldershot: Ashgate.

UCL. (2009). University College London. Using Moodle Quizzes for Online Exams. Retrieved from http://www.ucl.ac.uk/isd/staff/e-learning/tools/moodle/policies/online_exams

Weber, A. (2009). E-learning in the Gulf Cooperation Council Countries (GCC): Problems and Prospects. In V. Uskov (Ed.). Web-Based Education 2009. London: Acta Press.

Weber, A. (2010a). The Development and Current Status of Web-Based Learning in Qatar and the GCC States. Occasional Papers. Doha, Qatar: Center for International and Regional Studies, Georgetown SFS.

Weber, A. (2010b). Educational Considerations in the Development of E-Health Systems in the Gulf Cooperation Council (GCC). In V. Uskov (Ed.). Web-Based Education 2010. Calgary, AB: IASTED.

Weber, A. (2010c). E-learning: A Necessity for the Overseas Branch Campus Student. Proceedings of $e$ CASE and e-Tech 2010. Taipei, Taiwan: Knowledge Association.

Young, J.R. (2009, May 22). Why Blackboard's plan to buy a rival sparked a campus uproar. Chronicle of Higher Education. Retrieved from http://chronicle.com/article/Why-Blackboard-s-Plan-to-Buy/44375 


\section{Appendix: Sample screen captures of interfaces of CMS's used in the study}

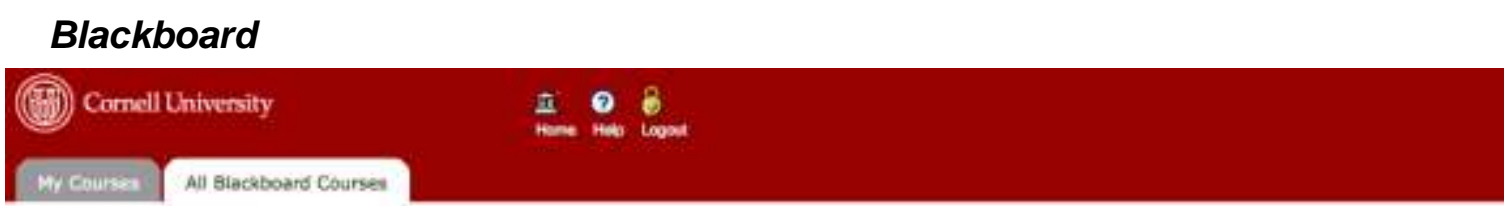

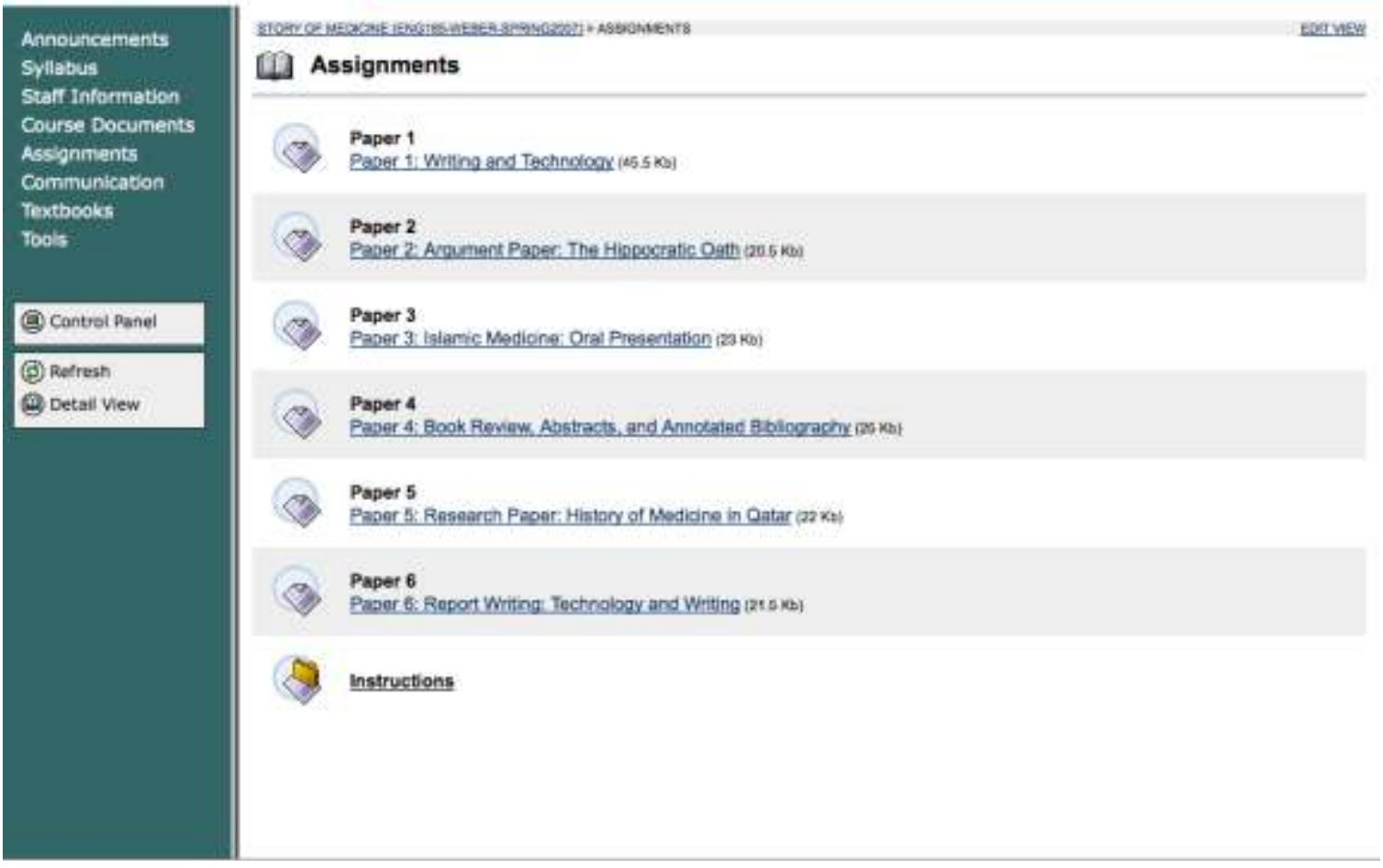

Weber, A. (2011). Arabic speakers' use of English language course management systems: a case study. 


\section{Moodle}

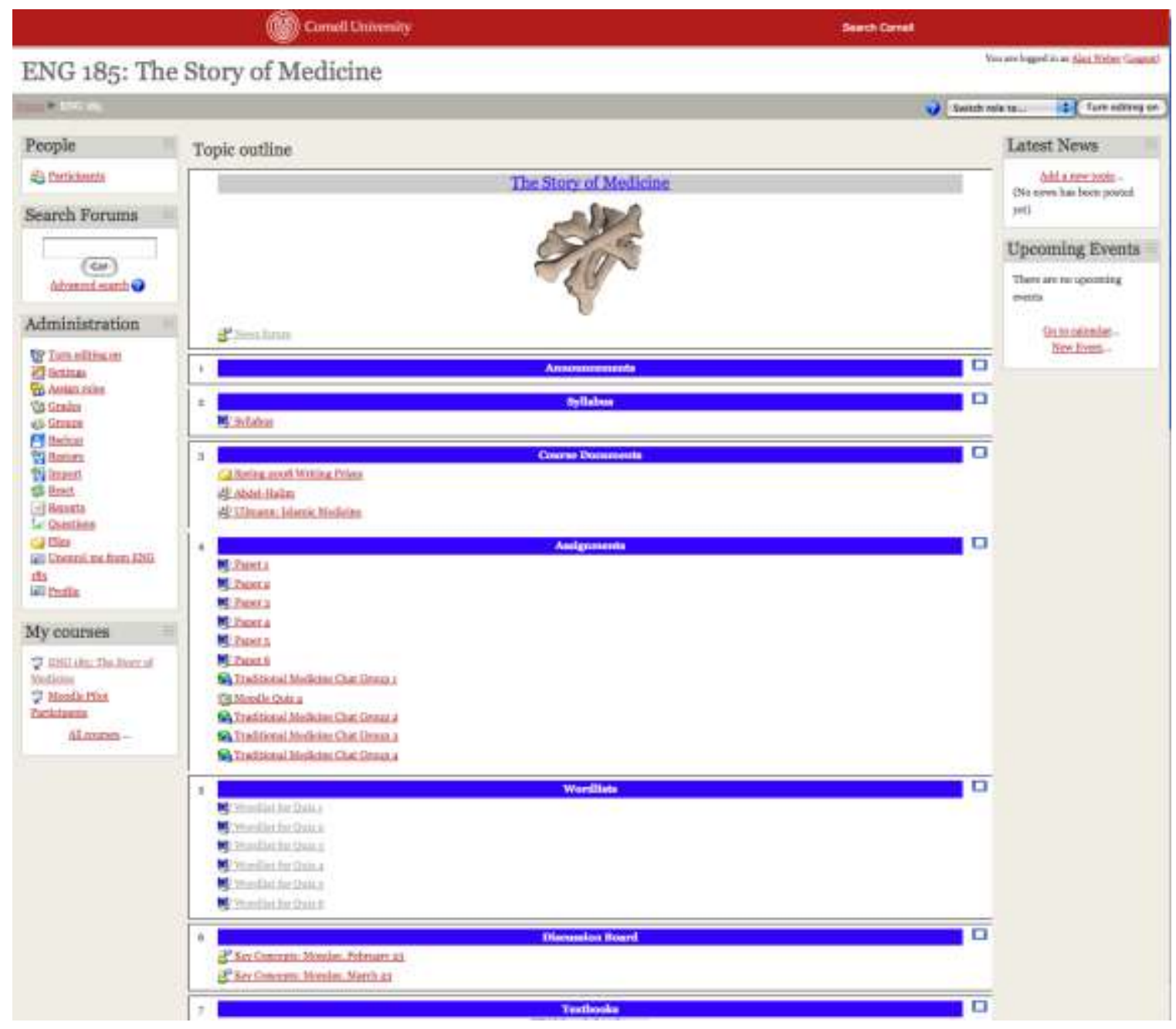

Weber, A. (2011). Arabic speakers' use of English language course management systems: a case study. 


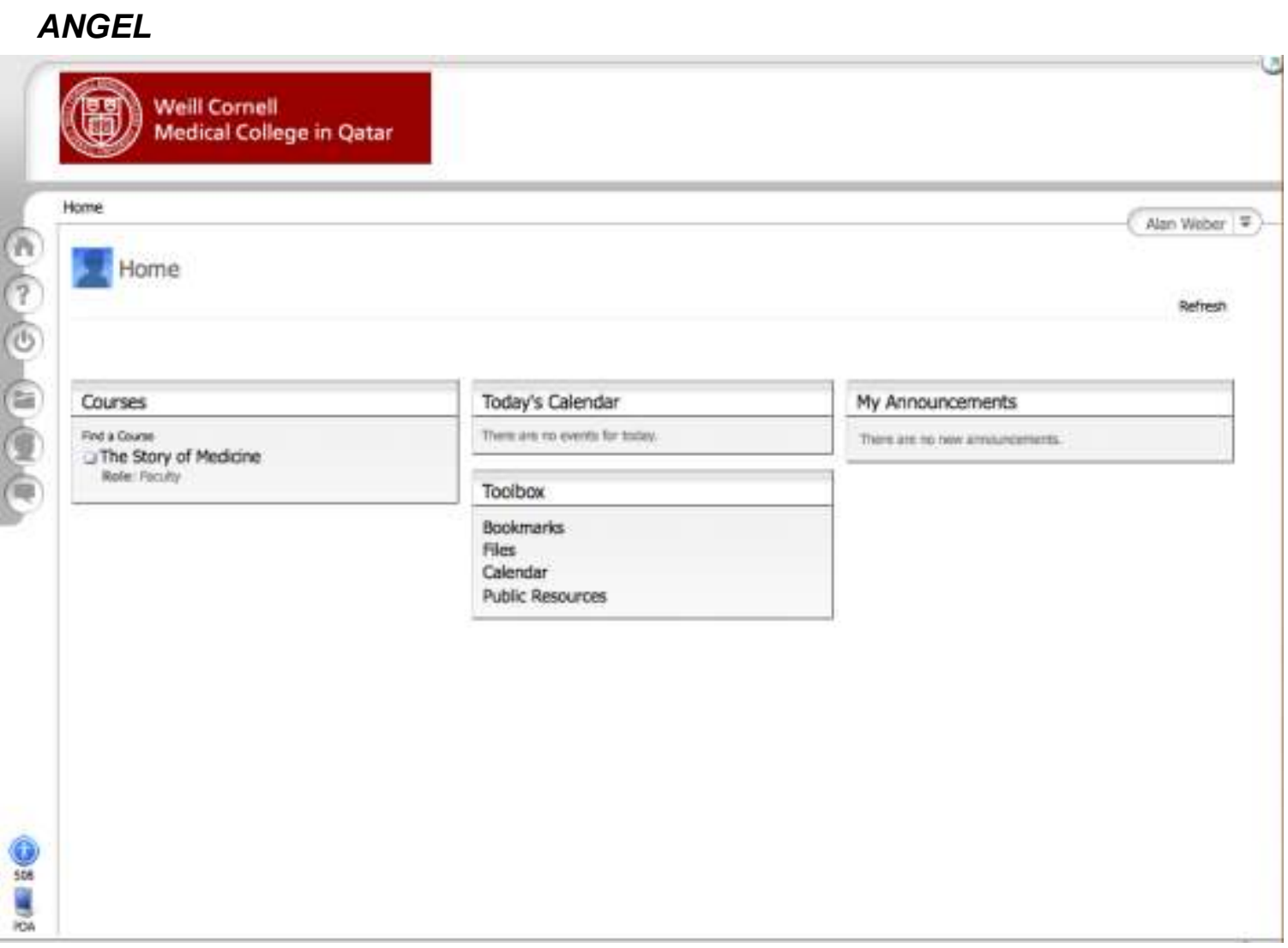

Weber, A. (2011). Arabic speakers' use of English language course management systems: a case study. Learning and Teaching in Higher Education: Gulf Perspectives, 8(1). 